\title{
CFD simulation and optimization of membrane scouring and nitrogen removal for an airlift external circulation membrane bioreactor
}

\author{
Min Yang a,b, Yuansong Wei ${ }^{\mathrm{a}, \mathrm{b}, *}$, Xiang Zheng ${ }^{\mathrm{c}}$, Fang Wang ${ }^{\mathrm{d}}$, Xing Yuan ${ }^{\mathrm{a}, \mathrm{b}}$, Jibao Liu ${ }^{\mathrm{a}, \mathrm{b}}$, Nan Luo ${ }^{\mathrm{a}, \mathrm{b}}$, \\ Rongle $\mathrm{Xu}^{\mathrm{a}, \mathrm{b}}$, Dawei $\mathrm{Yu}^{\mathrm{a}, \mathrm{b}}$, Yaobo Fan ${ }^{\mathrm{a}, \mathrm{b}, *}$

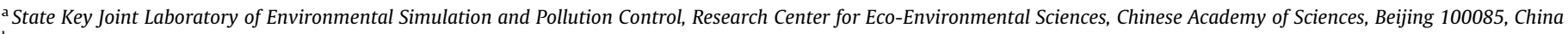 \\ ${ }^{\mathrm{b}}$ College of Resources and Environment, University of Chinese Academy of Sciences, Beijing 100049, China \\ 'School of Environment and Nature Resources, Renmin University of China, Beijing 100872, China \\ ${ }^{\mathrm{d}}$ School of Energy and Power Engineering, Beihang University, Beijing 100191, China
}

\section{H I G H L I G H T S}

- CFD model developed for the simulation and optimization of an AEC-MBR.

- Simplified bio-kinetics and sludge rheology incorporated within the CFD framework.

- The height of gas-liquid dispersion for membrane scouring was optimized.

- Simultaneous cost-effective membrane scouring and nitrogen removal achieved.

\section{A R T I C L E I N F O}

\section{Article history:}

Received 18 May 2016

Received in revised form 13 July 2016

Accepted 14 July 2016

Available online 2 August 2016

\section{Keywords:}

Membrane bioreactor

Oxygen mass transfer

Activated sludge model

Computational fluid dynamics

Particle image velocimetry

\begin{abstract}
A B S T R A C T
Cost-effective membrane fouling control and nitrogen removal performance are of great concern in airlift external circulation membrane bioreactors (AEC-MBRs). Computational fluid dynamics (CFD) model incorporating sub-models of bio-kinetics, oxygen transfer and sludge rheology was developed for the cost-effective optimization of a lab-scale AEC-MBR. The model was calibrated and validated by extensive measurements of water velocities and water quality parameters in the AEC-MBR. The validated results demonstrated that the optimized height of gas-liquid dispersion was at around $300 \mathrm{~mm}$. The shear stress on membrane surface was equalized and had an average value of $1.2 \mathrm{~Pa}$ under an air flowrate of $1.0 \mathrm{~m}^{3} \mathrm{~h}^{-1}$. The model further revealed that the high nitrogen removal efficiency (>90\%) was achieved due to the high recirculation ratio driven by airlift force without destroying the oxygen deprivation and enrichment in the anoxic and oxic zone, respectively.
\end{abstract}

(c) 2016 Published by Elsevier Ltd.

\section{Introduction}

Membrane bioreactors (MBRs) with different scales, types and structures have been widely used in wastewater treatment and reclamation because of the well-recognized advantages such as good and stable quality of effluent, less excess sludge production, flexible installation and small footprint (Judd, 2011; Wang et al., 2014). However, these advantages may be overshadowed by the high energy consumption of aeration and pumping (Fenu et al., 2010). For decades, researchers and practitioners have made great

\footnotetext{
* Corresponding authors at: State Key Joint Laboratory of Environmental Simulation and Pollution Control, Research Center for Eco-Environmental Sciences, Chinese Academy of Sciences, Beijing 100085, China.

E-mail addresses: yangmin1113@126.com (M. Yang),yswei@rcees.ac.cn (Y. Wei), ybfan@rcees.ac.cn (Y. Fan).
}

efforts to reduce the energy consumption and operating costs for MBR technology through process innovation and better operating strategy (Braak et al., 2011). Our previous work showed that the airlift external circulation MBR (AEC-MBR), which consists of an aeration tank and a membrane tank connected through holes in the clapboard separating the two tanks, was in a good performance for treating decentralized wastewater with lower energy consumption due to the lower aeration intensity and needless pumping (Fan et al., 2006). Continual innovations were made for the AEC-MBR application through membrane module design, membrane material modification and configuration optimization (Luo et al., 2015; Yuan et al., 2010; Zhang et al., 2013). Since 2003, this technology has been applied in more than 40 plants of wastewater treatment and reuse for public washrooms, hospitals, pharmaceutical factories and residential buildings in China (Zhang et al., 2013). Recently, we realized that the AEC-MBR can be converted to an 
alternative anoxic-oxic MBR system for nitrogen removal by replacing the aeration diffuser with paddle agitating in the aeration tank. A similar system called a multi-habitat MBR was proposed by (Tang et al., 2015, 2014). In their study, a high nitrogen removal rate was achieved due to the biodiversity and succession of the microbial community resulted from the formation of a multihabitat in a single MBR. However, the comprehensive action of the stirring paddle and the aeration taken for the formation of stable internal circulation, as they mentioned, was ambiguous. In fact, the quantification and optimization of the hydrodynamics such as stirring paddle speed and aeration intensity are the prerequisites for their successful operation.

Essentially, the key issue in such systems was how to create a hypoxia environment in anoxic unit while still meets the requirement of membrane scouring in membrane unit by the adjustment of configurations and operating conditions. DO concentration distribution, related to both sides and with quick response, is the most important and direct index for such adjustment. However, the numerical quantifying and controlling of DO distribution and water quality parameters in the AEC-MBR is missing. In principle, the evolvement of DO in bioreactor is a balance of oxygen transfer from gas to bulking liquid and oxygen consumption by microbial community. And it affects the removal performance of both organics and nutrients. Volumetric oxygen transfer rate (OTR) coefficient, $k_{L} \mathrm{a}$, is usually used for the description of oxygen source (Cockx et al., 2001). It is affected by many factors, such as configuration of bioreactor, surface tension, viscosity, temperature, and most importantly, the aeration condition including aeration intensity (Pittoors et al., 2014), aeration pattern (Capodici et al., 2015), bubble diameter and bubble shape (De Temmerman et al., 2015) and hydrodynamics(Braak et al., 2011). More than that, $k_{L}$ a is affected by the solution composition, biomass concentration and sludge rheological property in wastewater treatment systems (Pittoors et al., 2014).

Considering these factors together, CFD modeling for different bioreactor configurations, aeration devices and agitators in different types of bioreactors provided an excellent design tool for the optimization for distribution of DO concentration and other concerned components (Lei and $\mathrm{Ni}, 2014$ ). Activated sludge model (ASM), firstly developed for conventional activated sludge processes (Henze, 2000) and then extended in MBRs (Jiang et al., 2005), contains full description of oxygen consumption and transformation of other variables. It had been incorporated within the CFD framework to have a full understanding of the spatial distribution of DO as well as other water quality parameters in oxidation ditch, anoxic tank etc. (Brannock, 2003; Lei and Ni, 2014). However, simplification of full models are preferred for targetoriented and real-time control. The most straightforward model simplifications were obtained by assuming only oxic conditions while neglecting the denitrification processes. Markus (Gresch et al., 2011) studied the impact of aeration patterns on the flow field and the ammonia removal in a full scale aeration tank via integrating CFD with a single Monod expression for nitrification in which the DO concentration was presumed to be high enough to decouple the oxygen dynamics from the rest of the process dynamics. To enhance comprehensibility, Zhao et al. (1995) used a simplified ASM1 model to describe the ammonia and nitrate dynamics in an alternating activated sludge process. Zero-order reactions were adopted to represent the denitrification rate and the exchange between the soluble $\mathrm{NH}_{4}-\mathrm{N}$ and the organic nitrogen based on-line measurements. Along this line, Julien et al. (1999) developed a reduced order model containing two sub-models respectively for anoxic and oxic condition in a single tank through which the dynamics of the oxygen, ammonia and nitrate were only considered and the slower dynamics of the processes were frozen.
The simplex method of Nelder \& Mead was performed for identification of parameters of the model. Similar approach was thus adopted and the simplified model was incorporated within CFD in this study. A certain number of approximations were made from biochemical and mathematical considerations. The sensitive parameters involved in the bio-kinetic model were estimated by minimizing the sum of the squares of weighted deviations between measured data and calculations using the secant method embedded in AQUASIM (Reichert, 1995). Secant method allowed for all variables, compartments and calculations specified in the definition of parameter estimation, and over all data pairs of measured quantities for parameter estimation, which gave the user freedoms in defining the fit problem.

Besides, quantifying sludge rheological behavior to embed in the MBR process modeling for better model predictions is well worth the effort. Not only because the sludge rheological property has significant impact on oxygen transfer efficiency by retarding the fluid flow (Passos et al., 2015), but it plays an important role in membrane scouring in MBR due to the well-known power law function type relation between shear stress and sludge viscosity (Ratkovich et al., 2013).

However, to the best of our knowledge, the modeling of oxygen transfer and bio-kinetics with the consideration of sludge rheology within the CFD framework in the MBR simulation has not been reported. The objectives of this work are: (1) to develop an integrated CFD model with sub-models of oxygen transfer, simplified bio-kinetics and sludge rheology for the description of oxygen transfer and uptake, nitrogen transformation and membrane scouring, and (2) to simulate and optimize the configuration of membrane module to obtain a higher membrane scouring and appropriate DO distribution, and (3) to simulate and optimize the performance of nitrogen removal efficiency in the lab-scale AECMBR through the aeration adjustment. In this paper, CFD simulation and optimization of the height of gas-liquid dispersion and aeration intensity on membrane scouring and nitrogen removal was carried out with model calibrated and validated by extensive measurements of flow velocity and water quality parameters (Fig. 1).

\section{Materials and methods}

\subsection{Experimental setup and operational conditions}

Before the building up of the lab-scale AEC-MBR, the module configuration was optimized by modifying the height of gasliquid dispersion, $h_{m}$, which showed a good sensibility on membrane scouring in our previous study (Zhang et al., 2013). Here membrane shear stresses at different $h_{m}$ with a superficial aeration velocity of $50.0 \mathrm{~m}^{3} \mathrm{~h}^{-1}$ per $\mathrm{m}^{2}$ projected cross section area (SAR 50 ), which was the recommended value by the manufacturer (SINAP membrane tech Co., Ltd., China), were studied. According to the initial optimization, a lab-scale AEC-MBR with a work volume of 90.0 L was installed. It consists of an oxic tank (MBR tank) with the volume of $60.0 \mathrm{~L}$ and an anoxic tank with the volume of $30.0 \mathrm{~L}$ (Fig. 2). Five $0.07 \mathrm{~m}^{2}$ (effective filtration area $0.05 \mathrm{~m}^{2}$ for each membrane side) flat membrane sheets (SINAP membrane tech Co., Ltd., China) with a flux of $9.0 \mathrm{~L} \mathrm{~m}^{-2} \mathrm{~h}^{-1}$ were packed (Table 1). The configuration of the AEC-MBR and the sampling locations in this work were shown in Fig. 2. A clapboard with two connecting holes was inserted into a single tank, separating the tank into two units, anoxic unit and oxic unit, respectively. The membrane module was settled in the geometrical middle of the oxic unit. The two sides of each membrane sheet were named in forms of ' $\mathrm{m}_{i \mathrm{a}}$ ' and ' $\mathrm{m}_{i \mathrm{~b}}$ ', where ' $i$ ' was the membrane series number along 


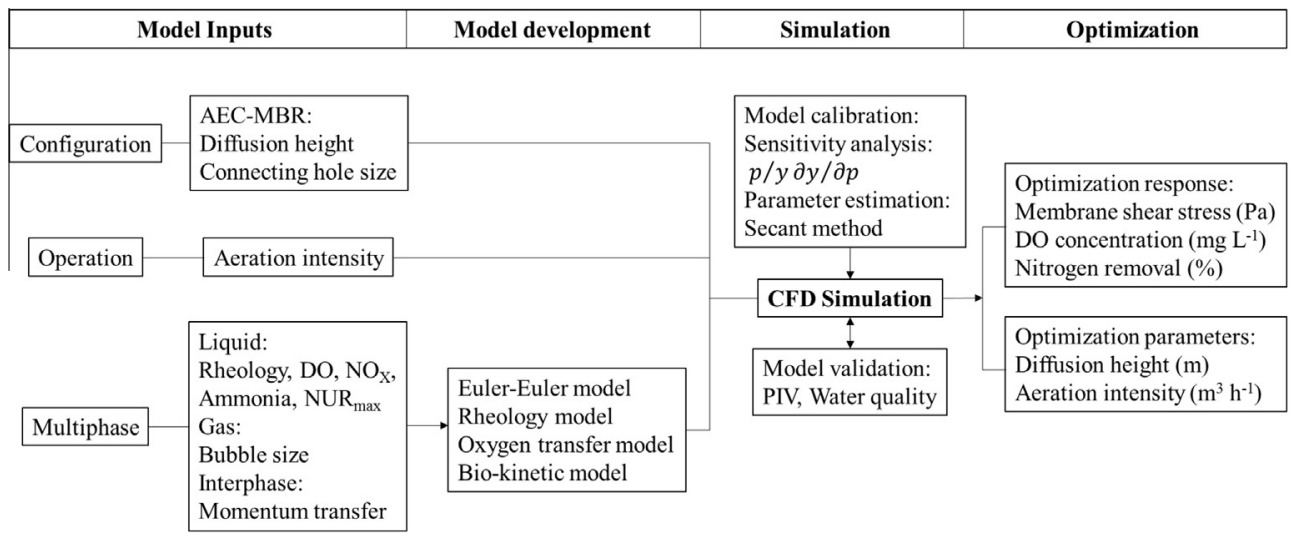

Fig. 1. Workflow diagram for CFD simulation and optimization of membrane scouring and nitrogen removal of the AEC-MBR.
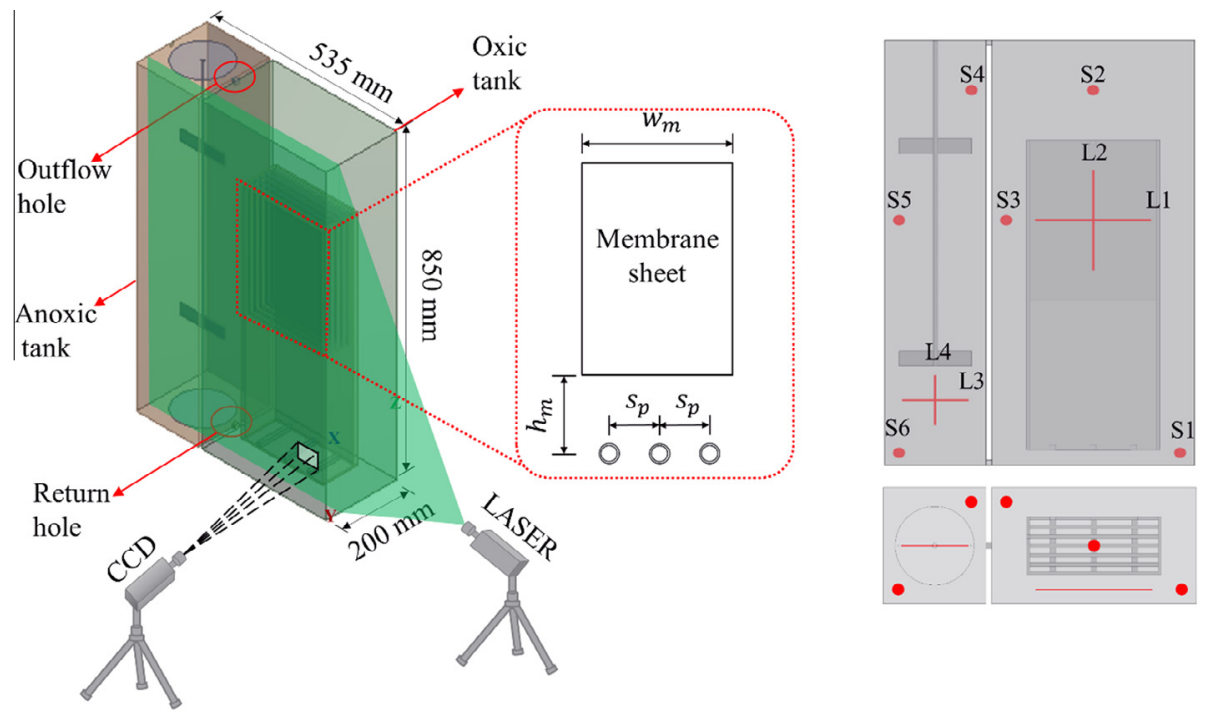

Fig. 2. Configuration and sampling locations of the lab-scale AEC-MBR.

Table 1

Geometry information and operation parameters of the lab-scale AEC-MBR.

\begin{tabular}{ll}
\hline Items & Sizes/parameters \\
\hline Treatment capacity & $108.0 \mathrm{~L} \mathrm{~d}^{-1}$ \\
Oxic tank $(\mathrm{L} \times \mathrm{W} \times \mathrm{H})$ & $350.0 \mathrm{~mm} \times 200.0 \mathrm{~mm} \times 1000.0 \mathrm{~mm}$ \\
Anoxic tank $(\mathrm{L} \times \mathrm{W} \times \mathrm{H})$ & $175.0 \mathrm{~mm} \times 200.0 \mathrm{~mm} \times 1000.0 \mathrm{~mm}$ \\
Membrane module & $220.0 \mathrm{~mm} \times 100.0 \mathrm{~mm} \times 320.0 \mathrm{~mm}$ \\
$\quad(\mathrm{~L} \times \mathrm{W} \times \mathrm{H})$ & \\
Membranes' interval $(\mathrm{mm})$ & 10.0 \\
HRT $(\mathrm{h})$ & 20.0 \\
SRT (day) & 20.0 \\
Flat sheet membrane & $220.0 \mathrm{~mm} \times 320.0 \mathrm{~mm} \times 6.0 \mathrm{~mm}$, PVDF, pore \\
$\quad(\mathrm{L} \times \mathrm{H} \times \mathrm{D})$ & size $0.1 \mu \mathrm{m}$ \\
Operation flux $\left(\mathrm{L} \mathrm{m}^{-2} \mathrm{~h}^{-1}\right)$ & 9.0 \\
Volume aeration intensity & $0.5(\mathrm{stage} 1), 1.5(\mathrm{stage} \mathrm{2}), 1.0$ (stage 3) \\
$\quad\left(\mathrm{m}^{3} \mathrm{~h}^{-1}\right)$ & \\
Orifice diameter $\left(\mathrm{mm}^{\mathrm{a}}\right)$ & 2.0 \\
Connecting hole diameter & 10.0 \\
$\quad(\mathrm{~mm})$ & $125.0 \mathrm{~mm} \times 30.0 \mathrm{~mm} \times 2.0 \mathrm{~mm}$, rotation \\
Agitator $(\mathrm{L} \times \mathrm{W} \times \mathrm{D})$ & speed at $60 \mathrm{rpm}$ \\
&
\end{tabular}

${ }^{\text {a }}$ Volume aeration intensity of $1.0 \mathrm{~m}^{3} \mathrm{~h}^{-1}$ is corresponded to the SAR 50 .

$y$ direction, and ' $a$ ' and ' $b$ ' indicated the front and back of each membrane sheet, respectively. The aeration diffusers were perpendicular to the membrane surfaces with a diffusers' interval $s_{p}$. The vertical distance of gas-liquid diffusion chamber, $h_{m}$, was prescribed as $300 \mathrm{~mm}$ according to CFD optimization. A double-flat blade agitator with a rotation speed at $60 \mathrm{rpm}$ in the anoxic tank was set for mixing. The wastewater was pumped from the feed tank into the anoxic unit with a peristaltic pump (YZ1515X-A, LONGER, China) controlled by a liquid level gauge. And treated wastewater was sucked out of the membranes by peristaltic pumps connected to pressure gauge (HSLT-PKGA23, HESHI TECH, China). The mixed liquor was driven by aeration and externally recycled between the two units through the overflow hole and return flow hole located at the top and bottom of the clapboard, respectively. At the same time, membrane sheets were scoured in the internal circulation in oxic tank. No recirculation sludge pump was needed in the entire process. The activated sludge was inoculated from a municipal wastewater treatment plant (WWTP) with a process of anoxic/anaerobic/oxic-MBR in Beijing, China. Initial concentration of mixed liquid suspended sludge (MLSS) in the AEC-MBR was around $3000 \mathrm{mg} \mathrm{L}^{-1}$. The synthetic wastewater was composed of $400 \mathrm{mg} \mathrm{L}^{-1}$ glucose (approximately $360 \mathrm{mg} \mathrm{L}^{-1} \mathrm{COD}$ ), $200 \mathrm{mg} \mathrm{L}^{-1} \quad \mathrm{CH}_{3} \mathrm{COONa}$ (approximately $190 \mathrm{mg} \mathrm{L}^{-1} \quad \mathrm{COD}$ ), $191 \mathrm{mg} \mathrm{L}^{-1} \quad \mathrm{NH}_{4} \mathrm{Cl}$ (50 mg L${ }^{-1}$ ammonium), $35 \mathrm{mg} \mathrm{L}^{-1} \quad \mathrm{KH}_{2} \mathrm{PO}_{4}$ (8 $\mathrm{mg} \mathrm{L}^{-1}$ total phosphorus), $100 \mathrm{mg} \mathrm{L}^{-1} \mathrm{MgSO}_{4} \cdot 7 \mathrm{H}_{2} \mathrm{O}, 50 \mathrm{mg} \mathrm{L}^{-1}$ $\mathrm{CaCl}_{2} \cdot 2 \mathrm{H}_{2} \mathrm{O}, 250 \mathrm{mg} \mathrm{L}^{-1} \mathrm{NaHCO}_{3}$ (300 mg L ${ }^{-1} \mathrm{CaCO}_{3}$ alkalinity) and $\mathrm{mg} \mathrm{L}^{-1}$ of trace element solution per liter wastewater. The 
trace element composed of $1500 \mathrm{mg} \mathrm{L}^{-1} \mathrm{FeCl}_{3} \cdot 7 \mathrm{H}_{2} \mathrm{O}, 150 \mathrm{mg} \mathrm{L}^{-1}$ $\mathrm{H}_{3} \mathrm{BO}_{4}, 30 \mathrm{mg} \mathrm{L}^{-1} \mathrm{CuSO}_{4} \cdot 5 \mathrm{H}_{2} \mathrm{O}, 180 \mathrm{mg} \mathrm{L}^{-1} \mathrm{KI}, 120 \mathrm{mg} \mathrm{L}^{-1} \mathrm{MnCl}_{2}-$ $.4 \mathrm{H}_{2} \mathrm{O}, \quad 60 \mathrm{mg} \mathrm{L}^{-1} \quad \mathrm{Na}_{2} \mathrm{MoO}_{4} \cdot 2 \mathrm{H}_{2} \mathrm{O}, \quad 120 \mathrm{mg} \mathrm{L}^{-1} \quad \mathrm{ZnSO}_{4} \cdot 7 \mathrm{H}_{2} \mathrm{O}$, $150 \mathrm{mg} \mathrm{L}^{-1} \mathrm{CoCl}_{2} \cdot 6 \mathrm{H}_{2} \mathrm{O}$ and $10,000 \mathrm{mg} \mathrm{L}^{-1}$ EDTA.

Hexahedral mesh was generated for the geometry of this set up by using ICEM 15.0 (ANSYS, USA). After the grid independent test, the optimized grid used in this work was around 288,000 elements with the maximum and minimum element sizes of $30.0 \mathrm{~mm}$ and $3.0 \mathrm{~mm}$, respectively. All the simulations were carried out in FLUENT 15.0 (ANSYS, USA) on a work station (Thinkstation D30, LENOVO, China) with a 64 bit processor (Intel ${ }^{\circledR}$ Core $^{\mathrm{TM}} 12$ Xeon CPU E5649) and $24 \mathrm{~GB}$ of random access memory, running at a clock speed of $2.53 \mathrm{GHz}$.

\subsection{Sampling and analysis}

Samples of effluent were collected once every two days to make sure the system was in a good condition and to know whether the system reached a steady state. DO concentrations were measured with a fluorescence DO meter (Multi 3410, WTW Co Ltd, German) at points of S1(25 mm, $175 \mathrm{~mm}, 25 \mathrm{~mm}), \mathrm{S} 2$ (175 mm, $100 \mathrm{~mm}, 750 \mathrm{~mm}), \mathrm{S} 3(325 \mathrm{~mm}, 25 \mathrm{~mm}, 500 \mathrm{~mm}), \mathrm{S} 4$ (385 mm, $25 \mathrm{~mm}, 750 \mathrm{~mm}), \mathrm{S} 5(510 \mathrm{~mm}, 175 \mathrm{~mm}, 500 \mathrm{~mm}), \mathrm{S} 6$ (510 mm, $175 \mathrm{~mm}, 25 \mathrm{~mm}$ ), respectively (Fig. 2). Mixed liquor samples at points of $\mathrm{S} 1 \sim \mathrm{S} 6$ were collected once a day for 20 days during steady stages. The samples were immediately centrifuged at $4{ }^{\circ} \mathrm{C}$, supernatant was then filtered with glass fiber filters with a pore size of $0.22 \mu \mathrm{m}$, and then stored at $4{ }^{\circ} \mathrm{C}$ for the measuring of COD, ammonia, nitrate, nitrite and total nitrogen. All measurements were carried out according to standard methods (APHA 2005) within one week after the sample collecting. The measured data were evaluated by Student's $t$-test paired with the $F$-test to determine the statistical significance of the observed differences between the measured data for DO, ammonia, nitrate and nitrite at the 95\% confidence level (Dochain and Vanrolleghem, 2001). After that, the average values were used for model calibration and validation.

Activated sludge samples for the determination of maximum nitrate uptake rate $\left(\mathrm{NUR}_{\max }\right)$ was taken from the steadily operated

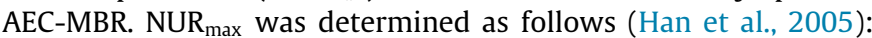
certain amounts of MLSS solution was taken out from the anoxic unit and was settled to remove the supernatant and placed on magnetic stirrer with a water bath $\left(20^{\circ} \mathrm{C}\right)$. The synthetic wastewater was added with the same volume of the withdrawn supernatant. First sample was taken immediately and filtered by $0.22 \mu \mathrm{m}$ glass fiber membrane. And following samples were taken and filtered at certain time points. Nitrate and nitrite concentration was measured after all samples were collected at once. Nitrification rate was calculated through linear regression in Origin ${ }^{\circledR}$ (Origin Lab, America).

Rheology of activated sludge samples from the AEC-MBR was measured by a Haake RS6000 Rheometer ${ }^{\circledR}$ (Thermo Scientific, USA). A double gap cylinder (DG41 Ti, $0.5 \mathrm{~mm}$ for each gap) was used as the measure geometry with torque resolution of $0.5 \mu \mathrm{Nm}$. The temperature of the samples was controlled at $20^{\circ} \mathrm{C} \pm 0.1^{\circ} \mathrm{C}$ through use of an circulating oil bath (SC150, Thermo Scientific, USA). The measurements were performed in triplicate at shear rates ranging from 0 to $500 \mathrm{~s}^{-1}$ after a $30 \mathrm{~s}$ strong shear with a shear stress of $500 \mathrm{~s}^{-1}$. The rheological data was logged to a PC and analysed using HAAKE RheoWin ${ }^{\mathrm{TM}}$ (3.50.0012, Thermo Scientific, USA). The non-Newtonian relationships between shear stress and shear rate were fitted to the yield-pseudoplastic type Sisko rheology model (Tang and Zhang, 2014) using Matlab ${ }^{\circledR}$ (Mathworks, Inc).

\section{CFD modeling}

\subsection{Model development}

\subsubsection{Governing equations}

The CFD model only included the gas-liquid phases in this study since the positive buoyancy forces from rising bubbles was much greater than the negative buoyancy forces of settling sludge, and the sludge showed a solid-liquid following features even the flocculating agent was added in the lab-scale MBR (Brannock et al., 2010a; Liu et al., 2015). The Euler-Euler model was used for the multiphase flow simulation. The steady-state continuity equation for phase $q$ is

$\nabla \cdot\left(\alpha_{q} \rho_{q} \vec{v}_{q}\right)=\dot{m}_{p q}-\dot{m}_{q p}$

where subscript $p$ and $q$ represent the gas phase and liquid phase, respectively. $\alpha_{q}$ is the volume fraction of phase $q, \rho_{q}\left(\mathrm{~kg} \mathrm{~m}^{-3}\right)$ is density of phase $q, \vec{v}_{q}\left(\mathrm{~m} \mathrm{~s}^{-1}\right)$ is velocity vector of phase $q, \dot{m}_{p q}$ $\left(\mathrm{kg} \mathrm{m}^{-3} \mathrm{~s}^{-1}\right)$ is the mass transfer source from phase $p$ to $q$. The steady-state momentum balance equation for the phase $q$ is

$$
\begin{aligned}
\nabla \cdot\left(\alpha_{q} \rho_{q} \vec{v}_{q} \vec{v}_{q}\right)= & -\alpha_{q} \nabla p+\nabla \cdot \vec{\tau}_{q}+\alpha_{q} \rho_{q} \\
& \times \vec{g}+\left(\vec{R}_{p q}+\dot{m}_{p q} \vec{v}_{p q}-\dot{m}_{q p} \vec{v}_{q p}\right)+\vec{F}_{q}
\end{aligned}
$$

where $p(\mathrm{~Pa})$ is the pressure shared by all phases, $\vec{v}_{p q}\left(\mathrm{~m} \mathrm{~s}^{-1}\right)$ is the interphase velocity, $\vec{R}_{p q}\left(\mathrm{~kg} \mathrm{~m}^{-2} \mathrm{~s}^{-2}\right)$ is an interaction force between phases, $\vec{F}_{q}\left(\mathrm{~kg} \mathrm{~m}^{-2} \mathrm{~s}^{-2}\right)$ is a buoyancy force.

The interphase momentum exchange coefficient for $\vec{R}_{p q}$ was determined by Schiller-Naumann drag model:

$C_{d}= \begin{cases}24 / \operatorname{Re}\left(1+0.15 R e^{0.687}\right) & R e \leqslant 1000 \\ 0.44 & R e>1000\end{cases}$

where $C_{d}$ is the momentum exchange coefficient, Re is Reynolds number.

To describe the effects of turbulent fluctuations of velocities and scalar quantities in multiphase, the RNG $k-\varepsilon$ mixture turbulence model was applied as the closure model (ANSYS, 2014).

\subsubsection{Species transport equations}

The 3D steady-state species ( $\mathrm{DO}$, ammonia and $\mathrm{NO}_{\mathrm{X}}$ ) distribution in the AEC-MBR was predicted by solving the advectiondispersion species transport equation extended with an oxygen mass transfer rate (OTR) sub-model and Monod-like sub-models. The transport equation takes the form of

$\nabla\left(\alpha^{q} \rho^{q} \vec{v}^{q} Y_{i}^{q}\right)=\nabla\left(\alpha^{q} \vec{J}_{i}^{q}\right)+\alpha^{q} S_{i}^{q}-\dot{m}_{q^{i} p^{j}}$

where $Y_{i}^{q}$ is the mass fraction of species $i$ in phase $q, \vec{J}_{i}^{q}\left(\mathrm{~kg} \mathrm{~m}^{-2} \mathrm{~s}^{-1}\right)$ is the diffusion flux of species $i$ in phase $q, S_{i}^{q}\left(\mathrm{~kg} \mathrm{~m}^{-3} \mathrm{~s}^{-1}\right)$ is the rate of creation by addition from the dispersed phase plus any userdefined sources, $\dot{m}_{q^{i} p^{j}}\left(\mathrm{~kg} \mathrm{~m}^{-3} \mathrm{~s}^{-1}\right)$ is the mass transfer source between species $i$ and $j$ from phase $q$ to $p$.

3.1.2.1. Oxygen mass transfer. The oxygen transfer rate (OTR) corresponding to $\dot{m}_{q^{i} p^{j}}$ in Eq. (3) can be expressed as (Pittoors et al., 2014)

$\mathrm{OTR}=k_{L} \mathrm{a}\left(\alpha \mathrm{S}_{\mathrm{O}}^{*}-\mathrm{S}_{\mathrm{O}}\right)$ 
where $k_{L} \mathrm{a}\left(\mathrm{s}^{-1}\right)$ is the mass transfer coefficient, $\alpha$ is the oxygen saturation concentration ratio of wastewater to clean water (Tchobanoglous et al., 2002), $\mathrm{S}_{\mathrm{O}}^{*}\left(\mathrm{mg} \mathrm{L}^{-1}\right)$ and $\mathrm{S}_{\mathrm{O}}\left(\mathrm{mg} \mathrm{L}^{-1}\right)$ are the dissolved oxygen saturation concentration of clean water and dissolved oxygen in the liquid phase.

For bubble-water interfaces, the penetration theory developed by Higbie were widely used for volumetric $k_{L}$ a description in pure water and in wastewater treatment. For the sludge bulking liquid, oxygen transfer is different from that in pure water. Being transferred into the wastewater, the oxygen was then transferred into the zoogleas and finally into the cells of microbes for metabolism (Arnaldos et al., 2015). MLSS concentration was found having an obvious effect on oxygen transfer by taking the vacancies of bubbles and changing their size and shape (Germain et al., 2007). The surfactants such as fatty acid and ethanol contained in the wastewater may lead a molecular film formation on the gasliquid interface, which will hinder the oxygen transfer (Ratkovich et al., 2013). Considering these effects, $k_{L}$ a was modified and took the form of (Cockx et al., 2001),

$k_{\mathrm{L}} \mathrm{a}=\beta \frac{12 \alpha_{\mathrm{b}}}{\mathrm{d}_{\mathrm{b}}} \sqrt{\frac{\mathrm{D}_{\mathrm{L}} \Delta \mathrm{U}}{\pi \mathrm{d}_{\mathrm{b}}}}$

where $\beta$ is the coefficient considering the effect of bulk liquid property, $\alpha_{b}$ is the gas volume fraction, $d_{b}(m)$ is the Sauter mean diameter of the bubbles, $D_{L}\left(\mathrm{~m}^{2} \mathrm{~s}^{-1}\right)$ is diffusivity of oxygen in the liquid phase, and $\Delta \mathrm{U}\left(\mathrm{m} \mathrm{s}^{-1}\right)$ is the slip velocity between bubbles and bulking liquid.

Mass transfer rate was affected by bubble shape and diameter evolution, which could be captured by using of interfacial area concentration model or Lagrangian approaches (Nopens et al., 2015). However, modeling of the coalescence and breakage of bubbles would significantly increase computational consumption and was not suitable for a steady-state simulation. So, a constant mean bubble diameter with no collisions, coalescence or breakage, which was a common acceptance in many previous CFD modeling of MBRs (Liu et al., 2015) as well as other bioreactors like bubble column (McClure et al., 2014), was assumed

$\mathrm{d}_{\mathrm{b}}=2.9 \alpha_{\mathrm{d}_{\mathrm{b}}}\left(\frac{\sigma \mathrm{d}_{0}}{\mathrm{~g} \rho_{\mathrm{L}}}\right)^{1 / 3}$

where $\alpha_{\mathrm{d}_{\mathrm{b}}}$ is a coefficient for the form of orifice, and $\sigma\left(\mathrm{N} \mathrm{m}^{-1}\right)$ is surface tension of liquid phase, $\mathrm{d}_{0}(\mathrm{~m})$ is diameter of orifice, $\mathrm{g}$ $\left(\mathrm{m} \mathrm{s}^{-2}\right)$ is gravitational acceleration, and $\rho_{\mathrm{L}}\left(\mathrm{kg} \mathrm{m}^{-3}\right)$ is the density of the liquid.

3.1.2.2. Biological kinetics of oxygen consumption and nitrogen transformation. In the ASMs framework, DO was presumed to be consumed for aerobic growth of heterotrophs and aerobic growth of autotrophs, which were affected by the concentrations of biomass and other substrates, which again involved in other kinetic processes (Henze, 2000). Since nitrogen transformation was mainly aimed in this study, only oxygen consumption, nitrification, denitrification and exchange of ammonia and organic nitrogen were described by simplified ASM1 (Zhao et al., 1995). Denitrification rate in anoxic unit, oxygen uptake rate in oxic unit and the exchange between the soluble $\mathrm{NH}_{4}-\mathrm{N}$ and the organic nitrogen in both units were identified with the initial value calculated via the full ASM1 model. Nitrification rate was defined as Eq. (10) in which the maximum specific nitrification rate of oxic unit was measured off-line.

The oxygen consumption corresponding to $S_{i}^{q}$ in Eq. (4) was simplified as

OUR $_{\text {Oxic }}=$ OUR $_{\text {Cons }}$
$\operatorname{OUR}_{\text {Anoxic }}=k_{1} \operatorname{OUR}_{\text {Cons }}\left(\frac{\mathrm{S}_{\mathrm{O}}}{\mathrm{K}_{\mathrm{OH}}+\mathrm{S}_{\mathrm{O}}}\right)$

where $\mathrm{K}_{\mathrm{OH}}\left(\mathrm{mg} \mathrm{L}^{-1}\right)$ is the half saturation constant of oxygen, $\mathrm{S}_{\mathrm{O}}$

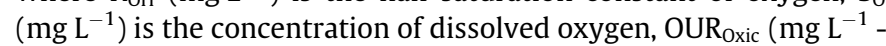
$\left.\mathrm{h}^{-1}\right)$ and $\operatorname{OUR}_{\text {Anoxic }}\left(\mathrm{mg} \mathrm{L}^{-1} \mathrm{~h}^{-1}\right)$ are the oxygen uptake rates in oxic unit and anoxic unit, respectively, OUR $\mathrm{O}_{\text {Cons }}\left(\mathrm{mg} \mathrm{L}^{-1} \mathrm{~h}^{-1}\right)$ is the constant oxygen uptake rate to be identified, $k_{1}$ is the coefficient of OUR in anoxic unit.

The denitrification rate was simplified as

$\mathrm{DNR}_{\text {Anoxic }}=\mathrm{DNR}_{\text {Cons }}$

$\mathrm{DNR}_{\text {Oxic }}=k_{2} \mathrm{DNR}_{\mathrm{Cons}}\left(\frac{\mathrm{K}_{\mathrm{OH}}}{\mathrm{K}_{\mathrm{OH}}+\mathrm{S}_{\mathrm{O}}}\right)$

Where $\operatorname{DNR}_{\text {Anoxic }}\left(\mathrm{mg} \mathrm{L}^{-1} \mathrm{~h}^{-1}\right)$ and $\mathrm{DNR}_{\text {Oxic }}\left(\mathrm{mg} \mathrm{L}^{-1} \mathrm{~h}^{-1}\right)$ are the denitrification rates in anoxic unit and oxic unit, respectively, $\mathrm{DNR}_{\text {Cons }}$ ( $\mathrm{mg} \mathrm{L}^{-1} \mathrm{~h}^{-1}$ ) is the constant denitrification rate to be identified, $k_{2}$ is the coefficient of DNR in the oxic unit.

The nitrification rate was defined by

$\mathrm{NUR}=\mathrm{NUR}_{\max }\left(\frac{\mathrm{S}_{\mathrm{NH}}}{\mathrm{K}_{\mathrm{NH}}+\mathrm{S}_{\mathrm{NH}}}\right)\left(\frac{\mathrm{S}_{\mathrm{O}}}{\mathrm{K}_{\mathrm{OA}}+\mathrm{S}_{\mathrm{O}}}\right)$

where NUR ( $\left.\mathrm{mg} \mathrm{L}^{-1} \mathrm{~h}^{-1}\right)$ is the nitrification rate, $\mathrm{NUR}_{\max }\left(\mathrm{mg} \mathrm{L}^{-1}\right.$ $\left.\mathrm{h}^{-1}\right)$ is the maximum nitrification rate, $\mathrm{K}_{\mathrm{NH}}\left(\mathrm{mg} \mathrm{L}^{-1}\right)$ is the ammonia half-saturation coefficient for heterotroph, and $\mathrm{S}_{\mathrm{NH}}\left(\mathrm{mg} \mathrm{L}^{-1}\right)$ is the concentration of ammonia, and $\mathrm{K}_{\mathrm{OA}}\left(\mathrm{mg} \mathrm{L}^{-1}\right)$ is the oxygen halfsaturation coefficient for heterotroph.

The exchange rates between ammonia and organic nitrogen were represented by zero-order equations as follows

$\mathrm{r}_{\mathrm{A}, \text { Oxic }}=\mathrm{R}_{\mathrm{A}, \text { Oxic }}$

$\mathrm{r}_{\mathrm{A}, \text { Anoxic }}=\mathrm{R}_{\mathrm{A}, \text { Anoxic }}$

Where $\mathrm{r}_{\mathrm{A} \text {,Oxic }}\left(\mathrm{mg} \mathrm{L}^{-1} \mathrm{~h}^{-1}\right)$ and $\mathrm{r}_{\mathrm{A} \text {,Anoxic }}\left(\mathrm{mg} \mathrm{L}^{-1} \mathrm{~h}^{-1}\right)$ are the exchange rate between ammonia and organic nitrogen in oxic unit and anoxic unit, respectively. $\mathrm{R}_{\mathrm{A}, \mathrm{Oxic}}\left(\mathrm{mg} \mathrm{L}^{-1} \mathrm{~h}^{-1}\right)$ and $\mathrm{R}_{\mathrm{A}, \mathrm{Anoxic}}\left(\mathrm{mg} \mathrm{L}^{-1} \mathrm{~h}^{-1}\right)$ are the constant values for $r_{A, O}$ and $r_{A, A}$, respectively.

\subsubsection{Shear stress. Shear stress was calculated by,}

$\tau_{i j}=\eta \overline{\bar{D}}=\eta\left(\frac{\partial u_{i}}{\partial x_{j}}+\frac{\partial u_{j}}{\partial x_{i}}\right)$

where $\tau_{i j}(\mathrm{~Pa})$ is shear stress, $\eta$ (Pa s) is apparent laminar viscosity, $\overline{\bar{D}}$ is rate-of-deformation tensor.

Apparent viscosity $\eta$ is a function of all three invariants of the rate-of-deformation tensor. A shear stress-shear rate relationship with MLSS of $7.5 \mathrm{~g} \mathrm{~L}^{-1}$ was measured for the estimation of $\eta$ and fitted to the Sisko model (Eshtiaghi et al., 2013) (Fig. S1).

$\eta=0.0012+0.071 \gamma^{-0.567} \quad \mathrm{R}^{2}=1.0$

where $\gamma\left(\mathrm{s}^{-1}\right)$ is the shear rate.

\subsection{Boundary conditions}

Membrane surfaces were treated as impermeable, stationary walls, which were free slip for air and no slip for liquid (Ndinisa et al., 2006; Yang et al., 2012). This assumption was based on the fact that the critical flux have little effect on the overall flow pattern and flat sheet membranes were non-oscillatory in lab-scale MBRs (Field and Pearce, 2011). The inlet of wastewater was positioned on the surface of anoxic tank. The outlet of wastewater was positioned on the membrane surfaces with an area of $0.0001 \mathrm{~m}^{2}$. Velocity inlet boundary was applied for air diffuser inlets, sewage inlet and sewage outlet, which were treated as plain 
surfaces with flow rates of mass equivalent to superficial mass velocities. The influent soluble species $S_{i}$ flux were prescribed accordingly. A degassing boundary condition was specified for the water-air surface (Brannock et al., 2010b). No slip boundary conditions were assigned for all other walls. The roughness constant and the roughness height at the no slip walls were default. The rotation by the submerged impeller in the anoxic unit was treated using multiple reference frame (Bannari et al., 2011). Residuals criteria of $1 \times 10^{-7}$ was used for convergence of equations involving species transport, and the default residuals criteria of $1 \times 10^{-3}$ was used for convergence of other variables. Flow velocity and concentration of $\mathrm{DO}$, ammonia and $\mathrm{NO}_{\mathrm{X}}$ at specific section were also monitored to make sure the simulation reaches a steady state.

\section{Results and discussion}

\subsection{Model calibration and validation}

Kinetic parameters $K_{\mathrm{OH}}$, reaction rates $\left(\mathrm{DNR}_{\mathrm{Cons}}\right.$, OUR $\mathrm{R}_{\mathrm{Cons}}$, $\mathrm{R}_{\mathrm{A} \text {,Anoxic }}, \mathrm{R}_{\mathrm{A}, \mathrm{Oxic}}$ ) and coefficient $k_{2}$ were found most sensitive by the relative sensitive analysis. Here, the average concentration of DO, ammonia and $\mathrm{NO}_{\mathrm{x}}$ measured in oxic tank and anoxic tank were used for the determination of model parameters with initial values of half saturation coefficients and with reaction rates given in the full ASM1 model. With the calibrated values (Table 2), the model gave the three state variables relative errors of $1.4 \%, 12.0 \%, 1.8 \%$ in oxic tank and $2.6 \%, 5.7 \%, 13.8 \%$ in anoxic tank (stage two), respectively.

Model validation of water velocity was carried out in the AECMBR at an airflow rate of $1.0 \mathrm{~m}^{3} \mathrm{~h}^{-1}$. A Particle Image Velocimetry (PIV) (EM3-03M1500, Microvec Pte. Co., LTD, China) was adopted. A certain amount of glass micro-beads (MV-H0105, Microvec Pte. Co., LTD, China) were injected into the reactor as the tracers to maintain an overall concentration of $10.0 \mathrm{mg} \mathrm{L}^{-1}$. Planar crosssections of $45.0 \mathrm{~mm} \times 30.0 \mathrm{~mm}$ were illuminated with a sheet light source (LWGL532081798, Microvec Pte. Co., LTD, China), and a high speed camera (SIGMA, Japan) taking 206 pictures per second was set up to capture the tracer particles for $15.0 \mathrm{~s} \times 3$ times at each cross-section. To eliminate bubble reflection effects, only water velocities outside the membrane module (L1 and L2) and water velocities in anoxic unit (L3 and L4) were recorded (Fig. 2). The simulation achieved steady states after a certain of iterations (Fig. S4). The simulated local water velocity in MBR tank demonstrated that the recirculation flow between the riser and downcomer was established (Fig. S5). With a larger crosssectional area, the observed downcomer had a much smaller water velocity than that in the riser. The even smaller water velocity near the wall and at the corner due to the wall friction and eddydissipation can be also observed (Fig. S5). An obvious two layers of water streamline in the anoxic unit made this unit more like a plug flow reactor (Fig. S5). A good agreement of water velocities between CFD simulations and PIV measurement results was achieved (Fig. 3). All relative errors were less than 5\% suggesting that the model provided a good description of flow behavior. Model validation of water qualities was carried out during the state stages. Concentration of DO, was measured twice a day with a flu- orescence DO meter (Multi 3410, WTW Co Ltd, German) at points of S1 S6 (Fig. 2). Concentrations of ammonia, nitrite and nitrate at points of $\mathrm{S} 1 \sim \mathrm{S} 6$ were measured and compared to simulations. Fig. S2 shows that the simulated results provided acceptable accurate representativeness of the water quality parameters of DO, ammonia and $\mathrm{NO}_{\mathrm{X}}$ compared to the measurements via a small modification in the parameter values (Table 2 ).

\subsection{Optimization of membrane module configuration}

High and even distribution of shear stresses on different membrane surfaces were preferred for alleviating membrane fouling (Wibisono et al., 2014). With that, MBR can be maintained with a lower superficial airflow rate, which, in this study, was helpful for energy saving and to keep the DO concentration low in anoxic unit. However, uneven distribution of shear stresses were often observed whenever the aeration diffuser was perpendicular (Ndinisa et al., 2006) or parallel (Liu et al., 2010) to the membrane surfaces. To get even shear stresses distribution on different membrane sheets, many approaches were studied including optimization of parameters in configurations (Kang et al., 2008) and in operation (Drews et al., 2010). One of the most effective approaches in our previous findings was to elevate the height of gas-liquid dispersion $h_{m}$ (Zhang et al., 2013). Here $h_{m}$ (from $150 \mathrm{~mm}$ to $600 \mathrm{~mm}$ ) with a superficial aeration velocity of SAR 50 were studied. As shown in Fig. 4, shear stress on different membrane surfaces distributed unevenly at $h_{m}=150 \mathrm{~mm}$, e.g., higher on the middle surfaces and lower on either side membranes. With the extension of $h_{m}$, the shear stress saw growth both on the middle and the side membranes. The shear stress at the utmost membranes surfaces $\left(\mathrm{m}_{1 \mathrm{a}}\right.$ and $\mathrm{m}_{5 \mathrm{~b}}$ ) increased faster than that of the middle ones with the increase of $h_{m}$ from $150 \mathrm{~mm}$ to $450 \mathrm{~mm}$, which finally enhanced and almost equalized the shear stresses on different membrane sheets at $h_{m}$ of $300 \mathrm{~mm}$ and $450 \mathrm{~mm}$ (Fig. S3). But when $h_{m}$ further extended to $600 \mathrm{~mm}$, the shear stresses dropped again. The possible reasons were that water velocities didn't fully developed at low $h_{m}$ whereas water velocities dropped at high $h_{m}$ due to the converting of kinetic energy into potential energy and friction head loss (Douek et al., 1998). Considering the $h_{m} 450 \mathrm{~mm}$ was spatial inefficiency and had a higher head loss, $h_{m}=300 \mathrm{~mm}$ was preferred in this case.

\subsection{Distribution of DO concentration}

For the description of the DO transportation and distribution, a 3D AEC-MBR was simulated by the integrated CFD model developed here. Fig. 5 shows the predicted distribution of DO, ammonia and $\mathrm{NO}_{\mathrm{X}}$ at a certain hydrodynamic condition with the corresponding experimental measurements. Necessary DO concentration distribution successfully achieved in the oxic tank and anoxic tank with DO concentration of $3.5 \mathrm{mg} \mathrm{L}^{-1}$ in the oxic unit and that of $0.01 \mathrm{mg} \mathrm{L}^{-1}$ in anoxic tank, respectively (Fig. 5B). The high recirculation $\left(R_{i}=1306 \%\right)$ didn't destroy the expected DO environment. In contrast, the nitrogen removal efficiencies turned out to be very high with the high internal recirculation ratios (Table 3 ). In a viewpoint of ASM1, aerobic environment is prerequisite for the growth of nitrifiers (autotrophs) in oxic unit where ammonia can be trans-

Table 2

Values of parameters for the case of SAR 50 and their variabilities for the three SARs.

\begin{tabular}{|c|c|c|c|c|c|c|c|c|c|c|}
\hline Parameters & DNR $_{\text {Cons }}$ & OUR $_{\text {Cons }}$ & $\mathrm{K}_{\mathrm{OH}}$ & $\mathrm{K}_{\mathrm{OA}}$ & $\mathrm{K}_{\mathrm{NH}}$ & $\mathrm{NUR}_{\max }$ & $\mathrm{R}_{\mathrm{A}, \text { Anoxic }}$ & $\mathrm{R}_{\mathrm{A} \text {, Oxic }}$ & $k_{1}$ & $k_{2}$ \\
\hline Values & 6.49 & 33.96 & 0.2 & 0.3 & 0.25 & 23.15 & -0.52 & 0.93 & 2.81 & 3.33 \\
\hline Variability & $28 \%$ & $21 \%$ & $20 \%$ & $0 \%$ & $0 \%$ & $0 \%$ & $43 \%$ & $48 \%$ & $0 \%$ & $28 \%$ \\
\hline
\end{tabular}



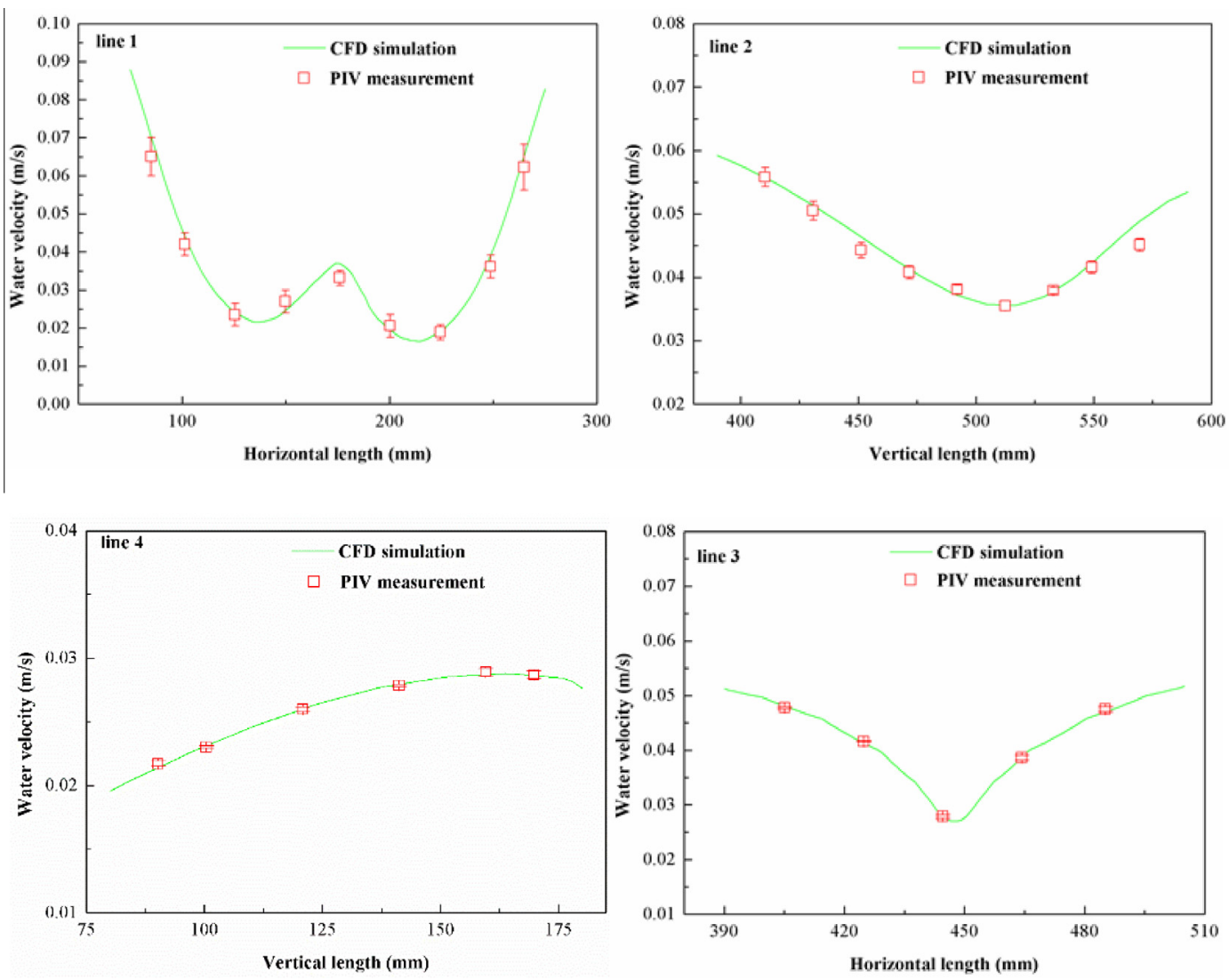

Fig. 3. Comparison of simulation and experimental results of water velocity in the AEC-MBR.

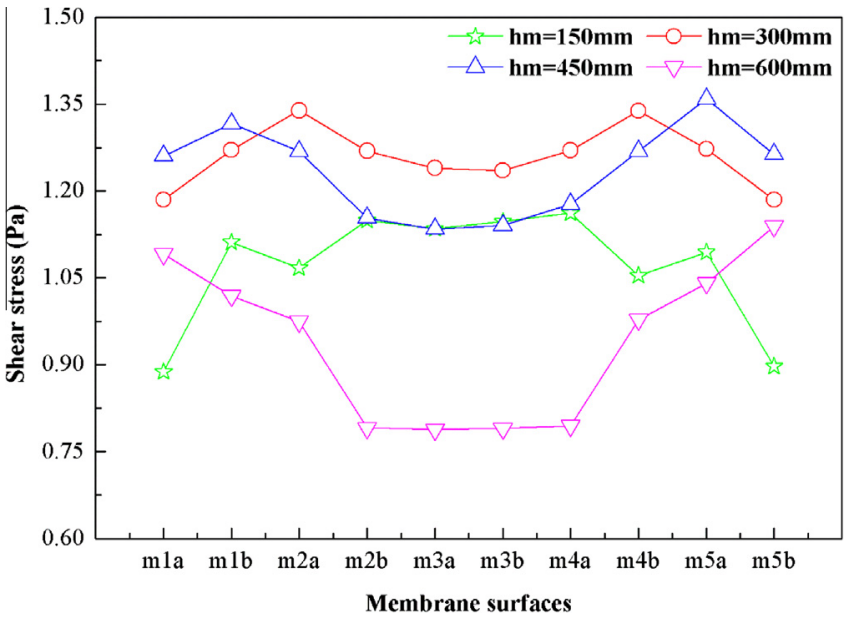

Fig. 4. Average shear stresses on membrane surfaces with different $h_{m}$ at SAR 50.

ferred to nitrate and nitrite, which would be transformed to nitrogen gas by denitrifiers (heterotrophs) in the anoxic condition given adequate substrates (Henze, 2000). Concentrations of TN in oxic unit of CFD simulation were nearly $2.8 \mathrm{mg} \mathrm{L}^{-1}$ (Fig. 5C and D), showed the removal ratio of TN was nearly $95 \%$, which fitted the theoretical value (Tchobanoglous et al., 2002), and thus confirmed the accuracy of the developed model (Table 3).

\subsection{Coordination of nitrogen removal and membrane scouring}

The nitrogen removal and membrane scouring was coordinated through the configuration modification and aeration adjustment since high aeration intensity was preferred for membrane scouring and ammonia removal but led to a detrimental high DO concentration in anoxic tank due to the high internal circulation ratio. For configuration modification, the optimization of gas-liquid dispersion height was carried out at first. Besides, the size of connecting hole was set to be small enough to respectively form oxygen deprivation and enrichment in the anoxic and oxic zone according to the hydraulic calculation in our previous study (Zhang et al., 2013).

The aeration intensity optimization of the AEC-MBR was then studied by tuning aeration intensities from SAR 25 to SAR 75 to balance the nitrogen removal and membrane scouring. The biokinetic parameters, which were case based and showed different variations (Table 2), were adjusted according to the measured data. The DO concentrations increased in both the anoxic and oxic units with the increase of SAR as expected, which can explain the differences of other species distribution in these two units. For ammonia, the increase of DO concentration led to a decrease of ammonia in the oxic unit, which further led to a dilution of ammonia in the anoxic unit when the liquid with low concentration of ammonia was recirculated. So a higher aeration intensity resulted in decrease of ammonia concentration in both units. Similar situation was found for $\mathrm{NO}_{\mathrm{X}}$ concentration in the oxic tank. The high recirculation rates led to a dilution of $\mathrm{NO}_{\mathrm{X}}$ concentration in the oxic unit when the liquid with low concentration of $\mathrm{NO}_{\mathrm{X}}$ from anoxic unit was recirculated. The lower $\mathrm{NO}_{\mathrm{X}}$ concentration of SAR 25 may be contributed to the simultaneous nitrification and denitrification due to the low DO concentration in oxic unit. But the $\mathrm{NO}_{\mathrm{X}}$ concentration in anoxic unit increased gradually due to the increase of DO and the homogenization between oxic tank and anoxic tank. As a result, further increase of aeration intensity would inhibit the denitrification process and lead to the system crash. At the same time, membrane shear stresses under different 


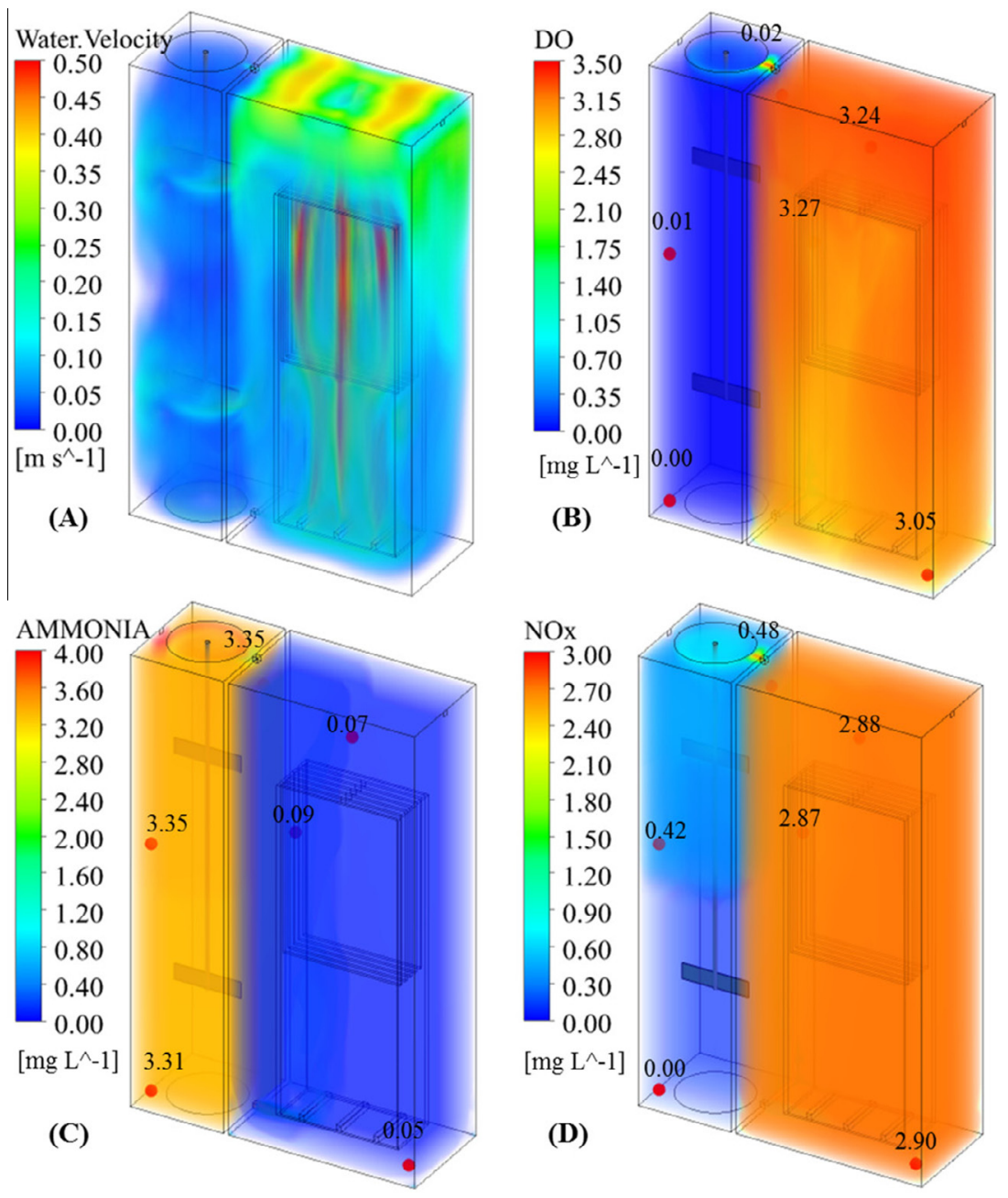

Fig. 5. Profiles of liquid velocity (A), DO (B), ammonia (C) and NOx (D) in the AEC-MBR at SAR 50.

Table 3

Performances of the AEC-MBR at different aeration intensities.

\begin{tabular}{|c|c|c|c|}
\hline Parameters & SAR 25 & SAR 50 & SAR 75 \\
\hline Average DO in oxic unit $\left(\mathrm{mg} \mathrm{L}^{-1}\right)$ & $0.97 \pm 0.14^{\mathrm{a}}$ & $3.10 \pm 0.24$ & $4.98 \pm 0.30$ \\
\hline Average DO in anoxic unit $\left(\mathrm{mg} \mathrm{L}^{-1}\right)$ & $0.004 \pm 0.04$ & $0.02 \pm 0.13$ & $0.08 \pm 0.22$ \\
\hline Average ammonia in oxic unit $\left(\mathrm{mg} \mathrm{L}^{-1}\right)$ & $0.11 \pm 0.16$ & $0.08 \pm 0.13$ & $0.05 \pm 0.10$ \\
\hline Average ammonia in anoxic unit ( $\left.\mathrm{mg} \mathrm{L}^{-1}\right)$ & $4.36 \pm 1.13$ & $3.41 \pm 1.19$ & $1.96 \pm 1.08$ \\
\hline Average $\mathrm{NO}_{\mathrm{X}}$ in oxic unit $\left(\mathrm{mg} \mathrm{L}^{-1}\right)$ & $2.72 \pm 0.18$ & $2.87 \pm 0.17$ & $2.36 \pm 0.11$ \\
\hline Average $\mathrm{NO}_{\mathrm{X}}$ in anoxic unit $\left(\mathrm{mg} \mathrm{L}^{-1}\right)$ & $0.10 \pm 0.14$ & $0.16 \pm 0.21$ & $0.52 \pm 0.28$ \\
\hline Removal ratio of total nitrogen (\%) & 94.8 & 94.6 & 95.6 \\
\hline Recirculation ratio (\%) & 1036 & 1306 & 1531 \\
\hline Average shear stress $(\mathrm{Pa})$ & $0.9 \pm 0.6^{\mathrm{b}}$ & $1.2 \pm 0.8$ & $1.4 \pm 0.8$ \\
\hline
\end{tabular}

a The standard deviations are the deviations of the species in the oxic or anoxic tank.

$\mathrm{b}$ The shear stress with a deviation obtained by averaging the shear stress at all membrane surfaces.

SARs were extracted from each membrane. The lowest shear stress occurred on the utmost surfaces of $m_{1 a}\left(m_{5 b}\right)$ while the highest occurred on surfaces of $\mathrm{m}_{1 \mathrm{~b}}\left(\mathrm{~m}_{5 \mathrm{a}}\right)$ in different SARs due to the Coanda effects (Mohd. Akbar et al., 2013). The difference of the two extreme values, however, was insignificant suggesting the success of configuration optimization (Fig. 6). Shear stresses were fitted to power-law correlation with aeration intensities due to the intrinsic relationship of shear stress and shear rate which linearly correlated to local water velocity near the membrane (Fig. 6) (Ratkovich et al., 2013). The derivative, $d$ (Shear stress)/d(SAR), of the fitting functions decrease monotonically suggested that the lower SAR, the higher shear stress efficiency. However, the SAR should be high enough to obtain sufficient shear stress to avoid membrane fouling. An average shear stress of $0.5 \mathrm{~Pa}$ in a full scale MBR was reported while an average shear stress of 0.6-0.7 Pa in a pilot scale MBR can be achieved with the dosing of flocculent, Fe (II) (Liu et al., 2015). The average membrane shear stress can be 0.5-2.0 Pa with $\mathrm{SAD}_{\mathrm{m}}=0.5-9.0 \mathrm{~m}^{3} \mathrm{~m}^{-2} \mathrm{~h}^{-1}$ in a lab-scale MBR (Yan et al., 2016, 2015). In this study, the shear stress of $0.9 \mathrm{~Pa}$ at SAR $25\left(\mathrm{SAD}_{\mathrm{m}}=1.0 \mathrm{~m}^{3} \mathrm{~m}^{-2} \mathrm{~h}^{-1}\right)$ was achieved. Operated at SAR 


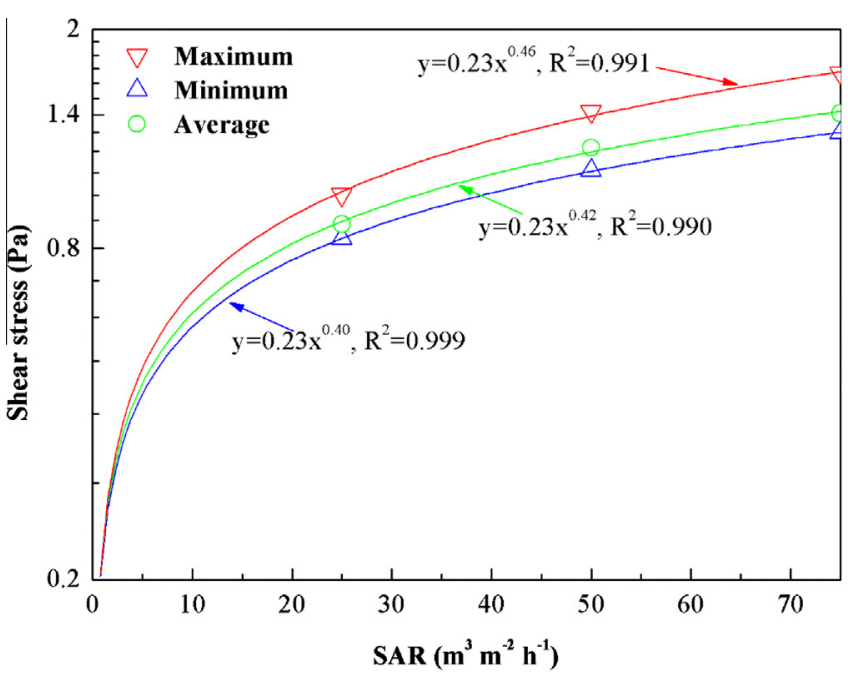

Fig. 6. Effects of aeration intensity on membrane surface shear stress with maximum on $\mathrm{m}_{1 \mathrm{~b}}$, minimum on $\mathrm{m}_{5 \mathrm{a}}$ and average of all membrane surfaces.

25 , the aeration energy can be reduced by $50.0 \%$ and $66.7 \%$ compared to SAR 50 and SAR 75, respectively. It should be noted, though, that these conclusions were based on the modeling of a lab-scale AEC-MBR which had a lower intensity of turbulence, a homogenous biomass distribution and a neglectable membrane oscillation and filtration. Large-scale MBR modeling by models considering both evolution of biomass and soluble species, and membrane oscillation and filtration is still needed.

\section{Conclusions}

A three dimensional CFD model was developed to simulate the multiphase dynamics and water quality in a lab-scale AEC-MBR. The proposed model was more target-oriented and thus calculation cheaper than full models. It gave an insight of membrane scouring and nitrogen transformation in the AEC-MBR system and was used for the system optimization. The cost-effective membrane scouring and nitrogen removal was achieved by the modification of gas-liquid dispersion height and aeration intensity. The results were suitable for lab-scale AEC-MBRs and further study is needed for large-scale MBRs considering evolution both for biomass and soluble species, membrane oscillation and filtration.

\section{Acknowledgements}

This work was supported by the National Natural Science Foundation of China (No. 51278483) and the Major Science and Technology Program for Water Pollution Control and Treatment of China (2015ZX07203-005).

\section{Appendix A. Supplementary data}

Supplementary data associated with this article can be found, in the online version, at http://dx.doi.org/10.1016/j.biortech.2016.07. 139.

\section{References}

ANSYS, 2014. FLUENT User's Guide. PERA GLOBAL, The United States.

APHA, 2005. Standard Methods for the Examination of Water and Wastewater, 21th ed. American Public Health Association, Washington, DC.

Arnaldos, M., Amerlinck, Y., Rehman, U., Maere, T., Van Hoey, S., Naessens, W., Nopens, I., 2015. From the affinity constant to the half-saturation index: understanding conventional modeling concepts in novel wastewater treatment processes. Water Res. 70, 458-470.

Bannari, R., Bannari, A., Selma, B., Proulx, P., 2011. Mass transfer and shear in an airlift bioreactor: using a mathematical model to improve reactor design and performance. Chem. Eng. Sci. 66, 2057-2067.

Braak, E., Alliet, M., Schetrite, S., Albasi, C., 2011. Aeration and hydrodynamics in submerged membrane bioreactors. J. Membr. Sci. 379, 1-18

Brannock, M., Leslie, G., Wang, Y., Buetehorn, S., 2010a. Optimising mixing and nutrient removal in membrane bioreactors: CFD modelling and experimental validation. Desalination 250, 815-818.

Brannock, M., Wang, Y., Leslie, G., 2010b. Mixing characterisation of full-scale membrane bioreactors: CFD modelling with experimental validation. Water Res. 44, 3181-3191.

Brannock, M.W.D., 2003. Computational Fluid Dynamics Tools for the Design of Mixed Anoxic Wastewater Treatment Vessels. University of Queensland.

Capodici, M., Di Bella, G., Di Trapani, D., Torregrossa, M., 2015. Pilot scale experiment with MBR operated in intermittent aeration condition: analysis of biological performance. Bioresour. Technol. 177, 398-405.

Cockx, A., Do-Quang, Z., Audic, J.M., Line, A., Roustan, M., 2001. Global and local mass transfer coefficients in waste water treatment process by computational fluid dynamics. Chem. Eng. Process. 40, 187-194.

De Temmerman, L., Maere, T., Temmink, H., Zwijnenburg, A., Nopens, I., 2015. The effect of fine bubble aeration intensity on membrane bioreactor sludge characteristics and fouling. Water Res. 76, 99-109.

Dochain, D., Vanrolleghem, P., 2001. Modelling and Estimation in Wastewater Treatment Processes. IWA Publishing, Colchester.

Douek, R.S., Clerc, A.X., Hewitt, G.F., Livingston, A.G., 1998. Hydrodynamics of threephase airuft(TPAL) reactors using viscous fluids. Chem. Eng. Commun. 167 205-225.

Drews, A., Prieske, H., Meyer, E.L., Senger, G., Kraume, M., 2010. Advantageous and detrimental effects of air sparging in membrane filtration: bubble movement, exerted shear and particle classification. Desalination 250, 1083-1086.

Eshtiaghi, N., Markis, F., Yap, S.D., Baudez, J.C., Slatter, P., 2013. Rheological characterisation of municipal sludge: a review. Water Res. 47, 5493-5510.

Fan, Y.B., Li, G., Wu, L.L., Yang, W.B., Dong, C.S., Xu, H.F., Fan, W., 2006. Treatment and reuse of toilet wastewater by an airlift external circulation membrane bioreactor. Process Biochem. 41, 1364-1370.

Fenu, A., Roels, J., Wambecq, T., De Gussem, K., Thoeye, C., De Gueldre, G., Van De Steene, B., 2010. Energy audit of a full scale MBR system. Desalination 262, 121 128.

Field, R.W., Pearce, G.K., 2011. Critical, sustainable and threshold fluxes for membrane filtration with water industry applications. Adv. Colloid Interface Sci. 164, 38-44.

Germain, E., Nelles, F., Drews, A., Pearce, P., Kraume, M., Reid, E., Judd, S.J. Stephenson, T., 2007. Biomass effects on oxygen transfer in membrane bioreactors. Water Res. 41, 1038-1044.

Gresch, M., Armbruster, M., Braun, D., Gujer, W., 2011. Effects of aeration patterns on the flow field in wastewater aeration tanks. Water Res. 45, 810-818.

Han, S.-S., Bae, T.-H., Jang, G.-G., Tak, T.-M., 2005. Influence of sludge retention time on membrane fouling and bioactivities in membrane bioreactor system. Process Biochem. 40, 2393-2400.

Henze, M., 2000. Activated sludge models: ASM1, ASM2, ASM2d and ASM3. International Water Association, The Kingdom of Netherlands.

Jiang, T., Liu, X., Kennedy, M.D., Schippers, J.C., Vanrolleghem, P.A., 2005. Calibrating a side-stream membrane bioreactor using Activated Sludge Model No. 1. Water Sci. Technol. 52, 359-367.

Judd, S., 2011. The MBR Book--Principles and Applications of Membrane Bioreactors for Water and Wastewater Treatment. Elsevier, UK.

Julien, S., Barbary, J.P., Lessard, P., 1999. A reduced order model for control of a single reactor activated sludge process. Math. Comput. Modell. Dyn. Syst. 5 337-350.

Kang, C.W., Hua, J.S., Lou, J., Liu, W.J., Jordan, E., 2008. Bridging the gap between membrane bio-reactor (MBR) pilot and plant studies. J. Membr. Sci. 325, $861-$ 871.

Lei, L., Ni, J., 2014. Three-dimensional three-phase model for simulation of hydrodynamics, oxygen mass transfer, carbon oxidation, nitrification and denitrification in an oxidation ditch. Water Res. 53, 200-214.

Liu, L.Y., Ding, Z.W., Lu, Y., Ma, R.Y., 2010. Modeling the bubbling enhanced microfiltration for submerged hollow fiber membrane module. Desalination $256,77-83$

Liu, X., Wang, Y., Waite, T.D., Leslie, G., 2015. Numerical simulation of bubble induced shear in membrane bioreactors: effects of mixed liquor rheology and membrane configuration. Water Res. 75, 131-145.

Luo, N., Xu, R., Yang, M., Yuan, X., Zhong, H., Fan, Y., 2015. Preparation and characterization of PVDF-glass fiber composite membrane reinforced by interfacial UV-grafting copolymerization. J. Environ. Sci. 38, 24-35.

McClure, D.D., Kavanagh, J.M., Fletcher, D.F., Barton, G.W., 2014. Development of a CFD model of bubble column bioreactors: part two - comparison of experimental data and CFD predictions. Chem. Eng. Technol. 37, 131-140.

Mohd. Akbar, M.H.b., Hayashi, K., Lucas, D., Tomiyama, A., 2013. Effects of inlet condition on flow structure of bubbly flow in a rectangular column. Chem. Eng. Sci. 104, 166-176.

Ndinisa, N.V., Fane, A.G., Wiley, D.E., Fletcher, D.F., 2006. Fouling control in a submerged flat sheet membrane system: Part II - two-Phase flow characterization and CFD simulations. Sep. Sci. Technol. 41, 1411-1445. 
Nopens, I., Torfs, E., Ducoste, J., Vanrolleghem, P.A., Gernaey, K.V., 2015. Population balance models: a useful complementary modelling framework for future WWTP modelling. Water Sci. Technol. 71, 159-167.

Passos, A.D., Voulgaropoulos, V.P., Paras, S.V., Mouza, A.A., 2015. The effect of surfactant addition on the performance of a bubble column containing a nonNewtonian liquid. Chem. Eng. Res. Des. 95, 93-104.

Pittoors, E., Guo, Y., Van Hulle, S.W.H., 2014. Oxygen transfer model development based on activated sludge and clean water in diffused aerated cylindrical tanks. Chem. Eng. J. 243, 51-59.

Ratkovich, N., Horn, W., Helmus, F.P., Rosenberger, S., Naessens, W., Nopens, I. Bentzen, T.R., 2013. Activated sludge rheology: a critical review on data collection and modelling. Water Res. 47, 463-482.

Reichert, P., 1995. AQUASIM - a tool for simulation and data analysis of aquatic systems. Water Sci. Technol. 30, 21-30.

Tang, B., Qiu, B., Huang, S., Yang, K., Bin, L., Fu, F., Yang, H., 2015. Distribution and mass transfer of dissolved oxygen in a multi-habitat membrane bioreactor. Bioresour. Technol. 182, 323-328.

Tang, B., Zhang, Z., 2014. Essence of disposing the excess sludge and optimizing the operation of wastewater treatment: rheological behavior and microbia ecosystem. Chemosphere 105, 1-13.

Tang, B., Zhang, Z., Chen, X., Bin, L., Huang, S., Fu, F., Yang, H., Chen, C., 2014 Biodiversity and succession of microbial community in a multi-habitat membrane bioreactor. Bioresour. Technol. 164, 354-361.

Tchobanoglous, G., Burton, F.L., Stensel, H.D., 2002. Wastewater Engineering: Treatment and Reuse. McGraw Hill Higher Education, Wakefield.
Wang, Z., Ma, J., Tang, C.Y., Kimura, K., Wang, Q., Han, X., 2014. Membrane cleaning in membrane bioreactors: a review. J. Membr. Sci. 468, 276-307.

Wibisono, Y., Cornelissen, E.R., Kemperman, A.J.B., van der Meer, W.G.J., Nijmeijer, K., 2014. Two-phase flow in membrane processes: a technology with a future. J. Membr. Sci. 453, 566-602.

Yan, X., Wu, Q., Sun, J., Liang, P., Zhang, X., Xiao, K., Huang, X., 2016. Hydrodynamic optimization of membrane bioreactor by horizontal geometry modification using computational fluid dynamics. Bioresour. Technol. 200, 328-334.

Yan, X., Xiao, K., Liang, S., Lei, T., Liang, P., Xue, T., Yu, K., Guan, J., Huang, X., 2015. Hydraulic optimization of membrane bioreactor via baffle modification using computational fluid dynamics. Bioresour. Technol. 175, 633-637.

Yang, J., Vedantam, S., Spanjers, H., Nopens, I., van Lier, J.B., 2012. Analysis of mass transfer characteristics in a tubular membrane using CFD modeling. Water Res. 46, 4705-4712.

Yuan, D., Fan, Y., Yu, Y., Xu, G., Yang, W., Wu, G., 2010. Study of a membrane bioreactor with glass fiber flat grille modules and the modules' optimization based on the local critical flux theory. Water Res. 44, 997-1005.

Zhang, Q., Xu, R., Zheng, X., Fan, Y., 2013. Simulation and optimization of airlift external circulation membrane bioreactor using computationalfluid dynamics. Water Sci. Technol. 69, 1846-1852.

Zhao, H., Isaacs, S.H., Soeberg, H., Kumme, M., 1995. An analysis of nitrogen removal and control strategies in an alternating activated sludge process. Water Res. 29 , 535-544. 